\title{
COMPARATIVE CHARACTERISTICS OF TREATMENT RESULTS USING THE OFFLOADING MEANS IN PATIENTS WITH PURULENT- NECROTIC COMPLICATIONS OF DIABETIC FOOT SYNDROME
}

DOI: 10.36740/WLek202108119

\author{
Rostyslav S. Shevchenko, Stanislav I. Shevchenko, Dmytro S. Pryimenko, Oksana S. Tsyganenko, Vladimir M. Feskov \\ KHARKIV NATIONAL MEDICAL UNIVERSITY, KHARKIV, UKRAINE
}

\begin{abstract}
The aim: To conduct a comparative analysis of clinical data, laboratory results, and pain intensity in patients using developed by us device for offloading the foot and plaster splint during inpatient treatment of purulent-necrotic complications of diabetic foot syndrome.

Materials and methods: We examined 76 patients with purulent-necrotic complications of diabetic foot syndrome, who used a plaster splint and a device for offloading the foot. We evaluated the clinical indicators of the healing process, laboratory data and pain intensity.

Results: Comparing the results of using the device for offloading the foot and the plaster splint showed that the developed by us device had a positive effect on the dynamics of the healing process: the edema disappeared on average 1.5 days earlier; the redness vanished on average 2.5 days earlier. We observed granulation and epithelialization significantly earlier $(p<0.05)$ than in the group where the plaster splint was used. The number of recorded surgical interventions was statistically significant and less $(p<0.05)$ in the group where our device was used. Low pain rates were in patients using a device for offloading the foot due to minimal contact of the wound surface with the floor. Conclusions: According to the results of comparative using the device for offloading the foot and plaster splint, we found out that using the device for offloading the foot allows creating statistically significant better conditions to accelerate wound healing in patients and reduce the duration of inpatient treatment.
\end{abstract}

KEY WORDS: diabetic foot syndrome, device for offloading the foot, plaster splint, purulent-necrotic complications, offloading of the foot

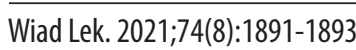

\section{INTRODUCTION}

Purulent-necrotic processes in the lower extremity in patients with diabetes are often characterized by severe clinical course and dangerous consequences for health and life. Diabetic foot syndrome (DFS) is a significant burden on the health care system of the country, negatively affecting the quality of life of patients and their relatives [1 - 3]. Due to the coronavirus, some patients delay visiting a doctor due to the fear of contracting COVID-19. Currently, there is a greater number of severe cases, serious complications, and the probability of high amputation is 3 times higher than before the pandemic [4].

To ensure a comprehensive approach to the DFS treatment, it is necessary to unload the lower extremity in order to reduce the mechanical pressure on the foot [5-7]. At the stage of inpatient treatment, there are various means of offloading the affected foot, but each of them has its drawbacks, which pushes researchers to find more effective solutions [8 - 10]. Therefore, the development and improvement of devices for offloading the lower extremity is a topical task.

\section{THE AIM}

The aim of the work is to conduct a comparative analysis of clinical data, laboratory results, and pain intensity in patients using developed by us device for offloading the foot and plaster splint during inpatient treatment of purulent-necrotic complications of diabetic foot syndrome.

\section{MATERIALS AND METHODS}

According to the results of complex treatment, 76 patients with purulent-necrotic complications of DFS were divided into two groups: the first group of patients used a continuous, windowless plaster splint applied from the fingertips to the upper third of the leg, and the second group of patients used a device for offloading the foot. The latter contains a sleeve formed on the shin of a polymeric material (Scotchcast and Soft Cast). The support element is made of wire; a strap and wheels are used. The first group included 35 patients. There were 19 women $(54.3 \%)$ and 16 men $(45.7 \%)$. The mean age of patients was $61.6 \pm 2.7$ years.

The second group consisted of 41 patients. There were $23(56.1 \%)$ women and $18(43.9 \%)$ men. The average age of patients of the second group was $62.3 \pm 2.4$ years.

At the beginning of the study, patients of both groups had stage 3 or 4 of the pathological process on the foot according to the Meggitt-Wagner classification [11]. All patients had a neuroischemic form of DFS. 
We found no statistically significant differences in age, sex and the nature of the pathological process on the foot in study groups. Before using the means of offloading the affected foot all patients were explained their feasibility and procedure.

The dynamics of the healing process was assessed by the following indicators: hyperemia, tissue edema and the nature of wound secretion, the timing of wound cleansing from necrotic tissue, the appearance of granulation tissue and the beginning of wound epithelization.

During the study, a general and biochemical blood test was performed. To assess the degree of endogenous intoxication and the state of immunological reactivity of the organism at different stages of purulent-necrotic process, the following hematological indices were calculated: leukocyte intoxication index by Calf-Caliph, blood leukocyte shift index, lymphocyte-granulocyte index.

The patients underwent cytological examination of wound impressions and bacteriological study of wound secretions. In order to assess pain in patients of study groups, a visual analog pain scale was used.

For statistical processing of the results, the mean value $(\mathrm{M})$ and the standard error of the mean value $(\mathrm{m})$ were calculated, the values at $\mathrm{p}<0.05$ were considered statistically significant using the program IBM SPSS Statistics, version 23

\section{RESULTS}

According to the results of comparative analysis of the dynamics of clinical criteria of the healing process and taking into account different means of offloading the lower extremity in study groups, we revealed differences in terms of disappearance of redness, swelling, wound cleansing, granulation, and epithelialization.

There was a disappearance of hyperemia in patients of the first group on $4.8 \pm 0.4$-day, swelling disappeared on $6.1 \pm 0.6$ day, a wound cleaning was fixed on $8.9 \pm 0.7$-day, emergence of granulation was noted on $11.0 \pm 0.8$-day, the beginning of epithelialization was observed on $12.9 \pm 0.7$-day.

In the group of patients who used the device for offloading the foot, the disappearance of redness occurred on $3.7 \pm 0.4$-day, edema disappeared on $4.5 \pm 0.5$-day, wound cleansing was recorded on $6.4 \pm 0.3$-day, the granulation appeared on $7.9 \pm 0.3$-day, the beginning of epithelialization was observed on $9.7 \pm 0.2$-day.

When assessing the dynamics of the healing process, we noted that using the device for offloading the foot can reduce the duration of wound cleansing by 2.5 days on average compared with the imposition of a plaster splint. Therefore, in the group of patients who used the device for offloading the foot, the granulation and epithelialization was observed significantly earlier $(\mathrm{p}<0.05)$ than in the group where a plaster splint was used.

Peripheral blood parameters and hematological indices did not differ statistically in patients of two groups.

The study revealed a tendency to reduce leukocytosis, reduce the shift of the leukocyte formula to the left by 20 days, which indicated the regression of the inflammatory process in the studied groups of patients. No statistically significant differences in hematological parameters were obtained.
We detected no significant differences in the microflora composition in patients of two study groups.

The initial bacterial contamination was $10^{5}-10^{7}$ microorganisms in 1 gram of tissue in both groups of patients. During repeated inoculation on the $10^{\text {th }}$ day of treatment, bacterial contamination of wounds decreased and amounted to $10^{3}$ microorganisms in 1 gram of tissue in the first group of patients and $10^{2}$ microorganisms in 1 gram of tissue in the second group.

According to the results of cytograms comparison on the $1^{\text {st }}, 5^{\text {th }}$ and $10^{\text {th }}$ day of the postoperative period, no significant differences were identified, because degenerative-inflammatory, inflammatory and inflammatory-regenerative types prevailed in the first and second group of patients, respectively.

On the $15^{\text {th }}$ day, the regenerative-inflammatory type of cytogram prevailed in the first group, the regenerative type was mostly observed in the second group. On the $20^{\text {th }}$ day, $81.8 \%$ of patients of the second group patients had a regenerative type of cytogram, $13.6 \%$ had a regenerative-inflammatory type, and only $4.6 \%$ had an inflammatory-regenerative type. The regenerative type of cytogram was recorded in $63.1 \%$ of patients in the first group.

In the first group, the progression of purulent-necrotic complications on the foot was observed in 7 patients and they were re-operated. When analyzing the results of treatment, we noticed that there were fewer repeated surgical interventions in the second group of patients, namely 2 operations. High amputations were not performed. This is a statistically significant result $(p<0.05)$ and a smaller number of recorded surgical interventions than in the first group.

In this group of patients, using a plaster splint, 3 patients fell down. Due to prolonged immobilization, we noted 4 cases of joint stiffness. 3 patients who wore a plaster splint, had a slight skin abrasion in the shin area, which did not affect the possibility of its further usage.

In the second group using a device for offloading the foot, we observed that 1 patient fell down and 2 patients had skin abrasions.

To identify the severity of pain among those patients who complained about pain, a visual analog pain scale was used. We identified 31 patients complaining about pain in the first group, and 37 patients in the second group. Having applied the visual analog pain scale, we obtained the following results: $4.7 \pm$ 1.5 and $5.3 \pm 1.7$, respectively.

\section{DISCUSSION}

Using the device for offloading the foot creates the conditions for accelerating the process of redness disappearance, which occurs on average 1 day earlier than in patients with a plaster splint. In the second group of patients, the swelling disappeared on average 1.5 days earlier than in the first group.

Having analyzed the hematological parameters in patients with purulent-necrotic complications of DFS on admission to the hospital, we noted neutrophilic leukocytosis, eosinopenia, lymphocytopenia, and an increased erythrocyte sedimentation rate.

In the study of the wound microflora structure in patients with purulent-necrotic complications of DFS at the time of 
admission to the hospital, we isolated both monocultures and microbial associations. Staphylococcus aureus, Streptococcus haemoliticus, Enterococcus faecalis, Staphylococcus epidermidis predominated among the microorganisms in the form of monoculture. The combination of two microorganisms is more common in the association [12].

The obtained results are consistent with the data on the duration of the inpatient treatment phase: the first group patients stayed in hospital $30.2 \pm 1.3$ days, the second group patients $-26.3 \pm 0.7$ days. These data indicate a decrease $(p<0.05)$ in the average duration of staying in hospital of patients who used the device for offloading the foot compared to the results of patients who used the plaster splint.

Using a plaster splint reduces the patient's mobility, it becomes more difficult to live normal life. A plaster splint on the lower extremity impairs the balance and coordination of movements, increases the likelihood of the patient's falling [8]. We should find a balance between physical activity and offloading helping patients manage diabetic foot syndrome $[7,10]$.

Despite the lack of statistical significance, the difference in visual analog pain scale between groups of patients, in our opinion, is associated with the degree of offloading of the lower extremity and the pressure exerted on the wound surface of the foot. When using the device developed by us, the contact of the wound surface with the floor is minimized, so these patients have low result according to visual analog pain scale. In addition, the combination of Scotchcast and Soft Cast materials ensures no injury to the shin skin with hard bandage edges.

\section{CONCLUSIONS}

1. Using a device for offloading the foot allows creating conditions for accelerating the healing process of wounds, as evidenced by a statistically significant difference in the incidence of granulation and the beginning of epithelialization $(\mathrm{p}<0.05)$.

2. The number of re-operations was smaller and statistically significant $(\mathrm{p}<0.05)$ in the second group, and the duration of inpatient treatment was less than in the group where patients used a plaster splint.

3. We detected no significant differences in blood parameters, hematological indices, microflora composition, and cytogram analysis.

4. The patients who used the device for offloading the foot had better results according to visual analog pain scale.

\section{REFERENCES}

1. Armstrong D.G., Boulton A.J.M., Bus S.A. Diabetic foot ulcers and their recurrence. N Engl J Med. 2017; 376:2367-2375.

2. Hicks C.W., Selvarajah S., Mathioudakis N. et al. Burden of Infected Diabetic Foot Ulcers on Hospital Admissions and Costs. Ann Vasc Surg. 2016;33:149-158.

3. Frykberg R.G., Banks J. Fed. Management of Diabetic Foot Ulcers: A Review. Pract. 2016; 33(2):16-23.

4. Casciato D.J., YancovitzS., Thompson J. et al. Diabetes-related major and minor amputation risk increased during the COVID-19 pandemic. J Am Podiatr Med Assoc. 2020;20:224. doi: https://doi.org/10.7547/20-224.
5. Finestone A.S., Tamir E., Ron G. et al. Surgical offloading procedures for diabetic foot ulcers compared to best non-surgical treatment: a study protocol for a randomized controlled trial. J Foot Ankle Res. 2018;11:6. doi: https://doi.org/10.1186/s13047-018-0248-3.

6. Sinacore D.R., Mueller M.J. Off-loading for diabetic foot disease. In: Bowker JH, Pfeifer MA, eds. Levin and $0^{\prime}$ Neal's the diabetic foot. 7th ed. Philadelphia: Mosby; 2008, p. 287-304.

7. Yalla S.V., Crews R.T., Patel N.A. et al. Offloading for the Diabetic Foot: Considerations and Implications. Clin Podiatr Med Surg. 2020;37(2):371384.

8. Kosulnykov S.O., Besedyn A.M., Kravchenko K.V. et al. Vybor sposoba ymmobylyzatsyy u bolnkh s syndromom dyabetycheskoi stopy [The choice of immobilization method in patients with diabetic foot syndrome]. International Endocrinological Journal 2010;(1):82-84. (In Russian).

9. Obolenskyi V.N., Nykytyn V.H., Leval P.Sh. et al. Lechebnodyahnostycheskyi alhorytm pry syndrome dyabetycheskoi stopy: standarti y novie tekhnolohyy [Therapeutic and diagnostic algorithm for diabetic foot syndrome: standards and new technologies]. International Endocrinological Journal 2012;45(5):81-94. (In Russian).

10. Mrdjenovich D.E. Off-loading practices for the wounded foot: concepts and choices. J Am Col CertifWound Spec. 2010;2(4):73-8. doi: https:// doi.org/10.1016/j.jcws.2011.02.001.

11. Wagner F.W. The dysvascular foot: A system for diagnosis and treatment Foot Ankle. 1981;2(2):64-122.

12. Kalachev E.V., Butyrskij A.G., Vlasov N.V. Osobennosti khirurgicheskoj infekcii pri gnojno-nekroticheskikh oslozhneniyakh sindroma diabeticheskoj stopy [Features of surgical infection with purulentnecrotic complications of diabetic foot syndrome]. Modern medical technologies 2013;(3):68-70. (In Russian).

\section{ORCID and contributionship:}

Rostyslav S. Shevchenko: 0000-0002-6535-0939 A,B,E

Stanislav I. Shevchenko: 0000-0001-5905-3017 A,F

Dmytro S. Pryimenko: 0000-0001-9650-5844 A,B,C,D,F

Oksana S. Tsyganenko: 0000-0003-3086-8073 ${ }^{\mathrm{C}}$

Vladimir M. Feskov: 0000-0002-0304-1209 ${ }^{B}$

\section{Conflict of interest:}

The Authors declare no conflict of interest.

\section{CORRESPONDING AUTHOR Dmytro S. Pryimenko \\ Kharkiv National Medical University \\ 4 Nauky Avenue, 61022 Kharkiv, Ukraine \\ tel: +380972906676 \\ e-mail:vsee@ua.fm}

Received: 21.03 .2021

Accepted: 29.07 .2021

\footnotetext{
A - Work concept and design, B - Data collection and analysis, C - Responsibility for statistical analysis,
}

D-Writing the article, $\mathbf{E}$-Critical review, $\mathbf{F}$-Final approval of the article 